\title{
ПОБУДОВА МАТЕМАТИЧНОЇ МОДЕЛІ СКЛАДНОГО РУХУ ФЛАКОНІВ НА ЛІНІЯХ РОЗЛИВУ ЛІКІВ ФАРМАЦЕВТИЧНОЇ ПРОМИСЛОВОСТІ
}

Н. О. Кравець

Тернопільський державний медичний університет імені І. Я. Горбачевського

\begin{abstract}
Представлена математична модель складного руху виробів вздовж бічних напрямних на ланці розподілу потоку пластинчастими конвеєрами на лініях розливу та здійснена експериментальна перевірка отриманих теоретичних залежностей. Результати розрахунків добре узгоджуються з результатами моделювання та експерименту.
\end{abstract}

Ключові слова: подільник потоку, лінія розливу, математична модель.

\section{ПОСТРОЕНИЕ МАТЕМАТИЧЕСКОЙ МОДЕЛИ СЛОЖНОГО ДВИЖЕНИЯ ФЛАКОНОВ В ЛИНИЯХ РАЗЛИВА ЛЕКАРСТВ ФАРМАЦЕВТИЧЕСКОЙ ПРОМЫШЛЕННОСТИ}

Н. О. Кравець

Тернопольский государственный медицинский университет имени И. Я. Горбачевского

\begin{abstract}
Представлена математическая модель сложного движения изделий вдоль боковых направляющих на звене распределения потока пластинчатыми конвеерами на линиях розлива и осуществлена экспериментальная проверка полученных теоретических зависимостей. Результаты расчетов хорошо согласуются с результатами моделирования и эксперимента.
\end{abstract}

Ключевые слова: разделитель потока, линия разлива, математическая модель.

\section{STRUCRURE OF THE MATHEMATICAL MODEL OF THE COMPLEX BOTTLES MOTION ON THE BOTTLES LINE IN THE PHARMACEUTICAL INDUSTRY}

N. O. Kravets

\author{
Ternopil State Medical University by I.Ya. Horbachevsky
}

The mathematical model of the complex product motion along the lateral lines at the plate conveyers of the bottle lines is presented in the artcle. The experimental evaluation of the gained theoretical dependence is suggested. The calculation results coordinate well with the modelling and experiment resuls.

Key words: divisor stream, bottles lines, mathematical model.

Постановка проблеми. У фармацевтичній промисловості все більшу роль відводять стану транспортно-технологічних систем (ТТС) на лініях розливу та фасування ліків. Це пов'язано зі зростаючим об'ємом продукції, яка випускається [1]. Найважливішою умовою при цьому є збільшення пропускної здатності при утриманні значень технологічних показників на необхідному рівні.

Характерною особливістю ліній розливу є використання однопотокових пластинчастих конвеєрів. Це викликано проектуванням ТТС $з$ мінімальним числом транспортних операцій, що обмежує зростання продуктивності [2]. Пластинчасті конвеєри на лініях розливу є тихохідними (0,02-0,1 м/с), так як швидкість проходження процесу розливу ліків суттєво залежить від пропускної здатності дозувальних пристроїв. Аналіз застосування типів та конструкцій дозувальних пристроїв поршневого типу, які використовуються на лініях розливу ліків, показав, що за їхніми технологічними параметрами є можливість здійснювати розлив в ємності місткістю 10-150 мл. Відповідно, час наповнення флаконів ліками різний. Це призводить до затримки тари на підвідних транспортерах, відповідно зростають навантаження на конструктивні елементи конвеєра, які, не забезпечивши терміну напрацювання, потребують ремонту чи заміни під час

() Н. О. Кравець 
експлуатації. Зменшення швидкісних параметрів ліній транспортування суттєво знижує продуктивність.

Вирішити цю проблему можливо за умови використання системи із декількома потоками. При цьому слід враховувати, що на лініях розливу ліків використовуються різні типорозміри склотари, а площі, через специфіку фармацевтичної галузі, є обмежені за санітарно-гігієнічними стандартами.

Аналіз останніх досліджень і публікацій. Аналіз літературних джерел по поставленій проблемі проводився за двома напрямками: вибір та аналіз обладнання для переходу на двопотокове транспортування скляної тари та складність математичного апарату для аналізу кінематичних та динамічних залежностей.

Апаратній реалізації розподілу потоку присвячені роботи А. І. Соколенка, О. Ю. Шевченко, С. М. Кожевнікова, Ф. К. Іванченка, Я. Г. Пановко [3-5]. В означених джерелах показано, що перехід від однопотокового до двопотокового позиціювання тари здійснюється за допомогою привідних або непривідних подільників. У першому випадку ділення потоку здійснюється примусово, під дією робочого органу, рух якого задається, а в непривідних - обкочуванням різних направляючих, планок і т.д. при переміщенні склотари за рахунок сил тертя між ними і несучим елементом транспортера. Автори зазначають, що використання привідних подільників використовується лише при детермінованому потоці руху вантажів; у випадку недетермінованого потоку задача ускладнюється. Також застосування дискових подільників потоку розраховано на встановлений діаметр тари циліндричної форми.
За випадків детермінованих підходів процеси розформування масивів організовуються на певних закономірностях за рахунок, наприклад, жорстких кінематичних зв'язків і послідовностей у виконанні окремих операцій. Не детерміновані підходи визначаються не прогнозованою послідовністю взаємодій між виробами, між виробами та бічними напрямними, рухомими та нерухомими упорами і т.д. Але у цьому випадку необхідно знайти такі конструктивні рішення, які б реалізовували задану пропускну здатність.

У зв'язку з цим актуальним є питання встановлення оптимальних кінематичних параметрів при використанні двопотокових ТТС, підвищення стабільності транспортування і зменшення питомої енергоємності та витрат на ремонт, забезпечуючи необхідну продуктивність.

Метою роботи $є$ встановлення залежностей між швидкісними характеристиками руху тари та конструктивними параметрами подільника потоку для унеможливлення затороутворення.

Матеріали і результати досліджень. Для рішення поставленої задачі використано запропонований автором пристрій [6] для розподілу потоку виробів, який включає підвідний і відвідні транспортери, нерухомі напрямні та орієнтатор (рис. 1). Відповідно до винаходу, орієнтатор виконаний у вигляді додаткового транспортера, розміщеного між відвідними транспортерами в продовження підвідного, причому привід додаткового транспортера кінематично зв'язаний 3 приводами відвідних з передаточним відношенням між додатковим і відвідними транспортерами більше 1, a caмe $1,1 \Gamma 1,3$.

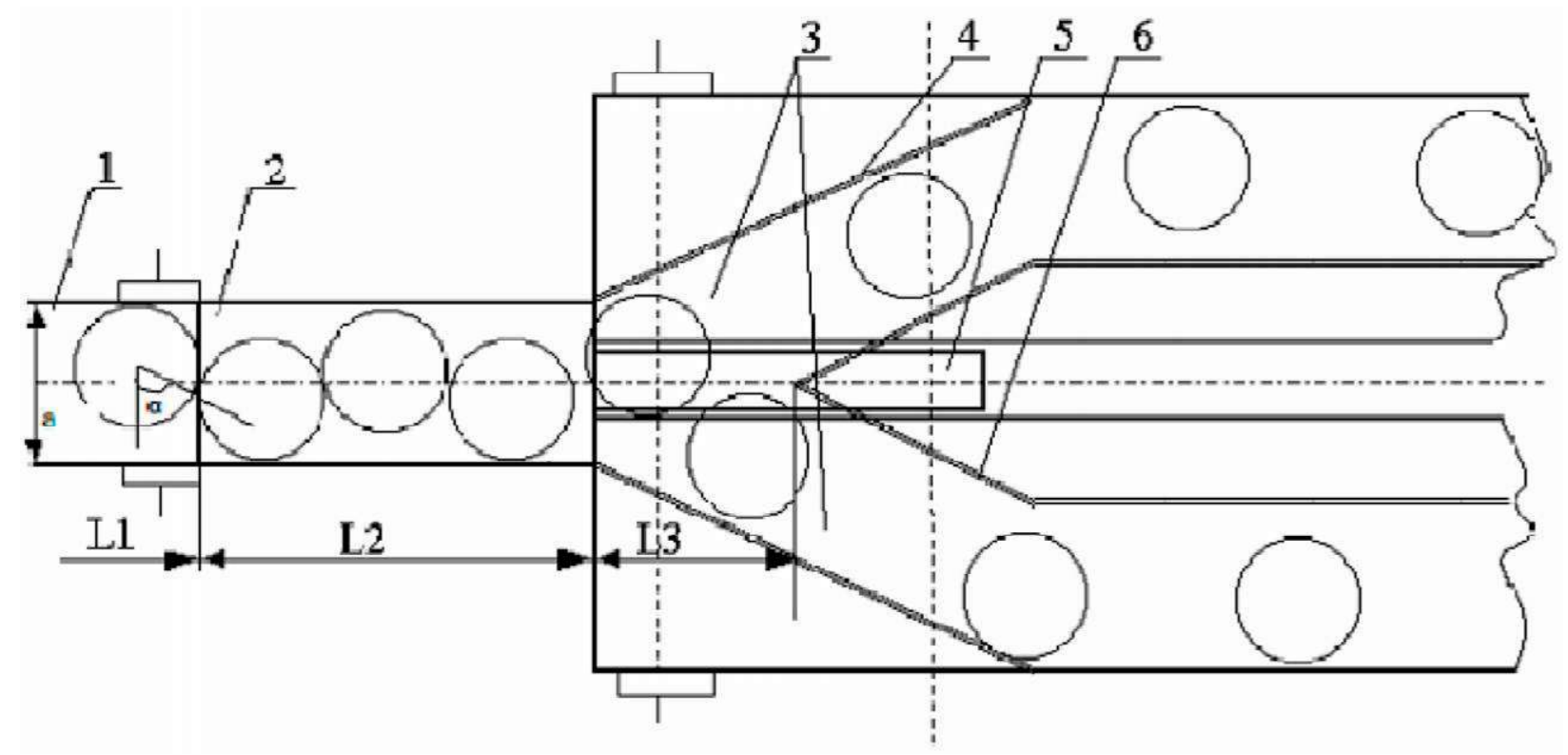

Puc. 1. Схема пристрою для розподілу потоку виробів. 
Пристрій для розподілу потоку виробів (рис. 1) складається 3 підвідного транспортера 1, перевантажувальної ланки 2, двох відвідних транспортерів 3, обмежувачів потоку 4, подільника потоку 6 та додаткового транспортера 5, встановленого в продовження підвідного транспортера 1 і розміщеного між відвідними транспортерами 3, причому додатковий транспортер 5 зв'язаний з відвідними транспортерами кінематичним вузлом 3 передаточним відношенням $1,3 \div 1,8$.

Коротко опишемо роботу. Потік виробів на підвідному транспортері 1 розміщується у „шахматному" порядку, тобто ширина транспортера становить 1,5 діаметра тари, що транспортується. Вироби 3 підвідного транспортера 1 за допомогою додаткового транспортера 5 подаються на відвідні транспортери 3. При цьому додатковий транспортер 5 утворює розподільчу поверхню, яка за рахунок допоміжного кінематичного вузла, що має передаточне відношення $1,1 \div 1,3$ - забезпечує додатковий імпульс руху виробів почергово на відвідні транспортери, тобто підвищення швидкості їх переміщення на відвідних транспортерах 3. Внаслідок цього на транспортерах 3 унеможливлюється виникнення заторів. Окрім того, на відвідних транспортерах 3 можуть одночасно виконуватися різні технологічні процеси.

Визначення кінематики переміщення флакона вздовж косої напрямної. На етапі розподілу 3 подільником потоку 3 використанням додаткового конвеєра, рух флакона контактує з опорною площиною за дугою кола і одночасно здійснює обертальний рух з частотою та поступальний рух зі швидкістю центра мас (рис. 1).

На рисунку 2 представлено розрахункову схему для визначення рушійного моменту та моменту сил тертя опору з опорною площиною.

В точках А та A' лінії контакту флакона $з$ опорною площиною виберемо елементарні ділянки з довжиною

Числове значення сили тертя знайдемо з виразу

$d F=f_{0} \cdot q \cdot d l$,

де $f_{0}$ - коефіцієнт тертя 3 опорною площиною; $q$ питомий тиск: $q=\frac{m \cdot g}{2 \cdot \pi \cdot R}, \mathrm{R}$ - радіус кола контактної лінії.

$$
\text { Тоді }
$$

$d F=\frac{f_{0} \cdot m \cdot g}{2 \cdot \pi \cdot R} d l$.

Елементарний момент від сили тертя $d F$

$$
d M=d F \cdot h_{\mathrm{KB}},
$$

де $h_{\text {кв }}$ - відстань від точки В контакту флакона 3 напрямною до лінії дії вектора елементарної сили тертя. Підставивши (2) в (3) отримаємо

$d M=\frac{f_{0} \cdot m \cdot g}{2 \cdot \pi \cdot R} \cdot h_{\mathrm{KB}} d l$.

У виразі (4) змінною є величина $h_{\text {л厂 }}$ яка залежить від $\beta, R, V, \varphi R$, де $\varphi$ - кутова швидкість обертального руху флакона.

Як видно з рис. 2, елементарна складова сили тертя $\mathrm{dF}$ створює протидіючий обертанню момент, а в точці $\mathrm{dF}^{\prime}$ - рушійний. Для нашого випадку маємо $\bar{V}_{\mathrm{n}}=\overline{V_{\text {I }}}+\overline{\dot{\varphi}} \bar{R}$.

Так як напрямок і значення швидкості $\bar{V}_{д} \epsilon$ фіксованими, плече елементарної сили $d F\left(\mathrm{~h}_{\mathrm{kB}}\right)$ знайдемо за виразом

$h_{\mathrm{KB}}=\rho \cdot \sin (\gamma)$,

де $\rho$ - радіус-вектор обертання флакона вздовж бічної напрямної. Як видно з рис. 2 ,

$\gamma=90-\delta$.

Для трикутника $A D L$ кут при вершині $D$ рівний $90-\alpha_{1}$, тобто використавши теорему синусів отримуємо

$\frac{\dot{\varphi} R}{\sin \left(90-\alpha_{1}\right)}=\frac{V_{\partial}}{\sin (\delta)}$,

звідки

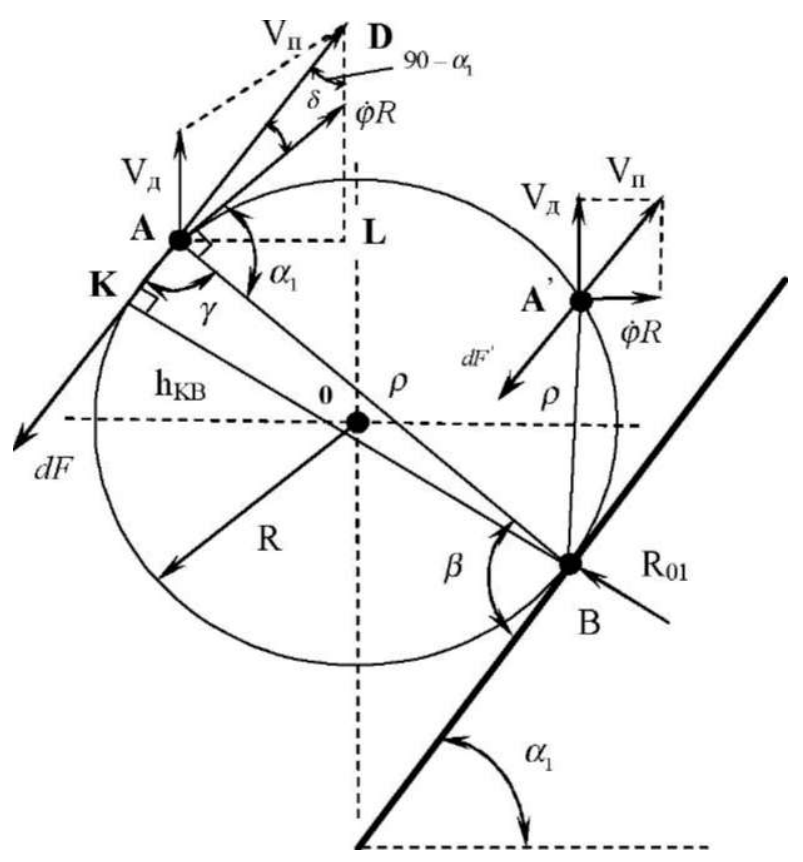

Puc. 2. Розрахункова схема для визначення параметрів руху флакона на подільнику потоку.

Медична інформатика та інженерія, № 4, 2010 
$\delta=\arcsin \left(\frac{V_{\text {д }} \cdot \sin \left(90-\alpha_{1}\right)}{\dot{\varphi} R}\right)=\arcsin \left(\frac{V_{\text {д }} \cdot \cos \left(\alpha_{1}\right)}{\dot{\varphi} R}\right)$

Підставивши вираз (9) в (7), з наступною підстановкою у вираз (6), отримаємо вираз для плеча елементарної сили $d F$

$$
\begin{aligned}
h_{\mathrm{KB}} & =\rho \cdot \sin \left(90^{\circ}-\arcsin \left(\frac{V_{\text {д }} \cdot \cos \left(\alpha_{1}\right)}{\dot{\varphi} R}\right) \cdot \quad \text { (10) } \begin{array}{r}
\text { Для кутів ар } \\
\text { чення моменту }
\end{array}\right. \\
M_{\text {руш }} & =\frac{2 f_{1} m g}{\pi} \int_{0}^{3 / 4^{\pi-\alpha_{1}}} \sin ^{2}(\beta) \cdot \sin \left(90^{\circ}-\arcsin \left(\frac{V_{д} \cdot \cos \left(\alpha_{1}\right)}{\dot{\varphi} R}\right)\right) \cdot d \beta
\end{aligned}
$$

Довжина радіуса-вектора р як функції кута в ме-

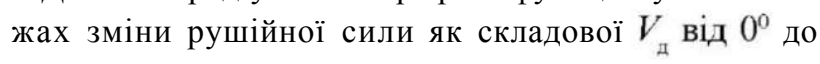
$3 / 4 \pi-\alpha_{1}$ визначається

$\rho=2 R \cos \left(90^{\circ}-\beta\right)=2 R \sin (\beta)$

Для кутів ab можна вважати: $d l=\rho d \beta$, тоді значення моменту рушійної сили знайдемо за виразом

Якщо позначити реакції бічної $R_{01}$ (рис. 2), то момент опору переміщення кочення

$M_{\text {оп }}=f_{1} \cdot R_{01}$,

$I \ddot{\varphi}=M_{\mathrm{pym}}=\frac{2 f_{1} m g}{\pi} \int_{0}^{3 / 4} \sin ^{2}(\beta) \cdot \sin \left(90^{\circ}-\arcsin \left(\frac{V_{\mathrm{I}} \cdot \cos \left(\alpha_{1}\right)}{\dot{\varphi} R}\right)\right) \cdot d \beta-f_{1} R_{01}$

Розв 'язання рівняння (14) виконується за початкових умов:

$$
t_{(\pi)}=0 ; \varphi_{(\pi)}=0 ; \dot{\varphi}_{(\pi)}=0 .
$$

Рівняння (15) розв'язуємо методом послідовних наближень, задавши величину ф та здійснюємо розв 'язання рівняння руху.

Методика проведення експериментальних досліджень та результати. Визначення кінематичних параметрів подільника потоку з застосуванням додаткового конвеєра проводились на лабораторному стенді (схема - рис.1) з використанням отриманих результатів виразу (15).

Дослідження полягали в визначенні часу переходу флаконів на відвідний конвеєр для встановлення необхідного позиціювання флакона на відвідному конвеєрі а також середньої швидкості переміщення флаконів вздовж бічної напрямної.

Дослідження проводились за наступною схемою (рис.1):

а) приводився в рух підвідний конвеєр;

б) встановлювався кут бічної напрямної $\alpha=45^{\circ}$; де $f_{1}$ - коефіцієнт тертя кочення.

Рівняння руху флакона на подільнику потоку записуємо у вигляді

в) приводився в рух відвідний конвеєр. Швидкість відвідного конвеєра плавним регулюванням встановлювалась, почергово, після виконання 5 досліджень на кожній із швидкостей у відповідності до швидкості

$V_{\text {д }}=1,1 V_{\text {п }} ; V_{\text {д }}=1,2 V_{\text {п }} ; V_{\text {д }}=1,3 V_{\text {п }} ;$

г) змінювалась швидкість привідного конвеєра в діапазоні із кроком $\Delta V=0,005 \mathrm{M} / \mathrm{c}$; виконувались дослідження за пунктом в;

д) встановлювався кут нахилу бічної напрямної а $=60^{\circ}$; виконувались дослідження за пунктами в та г.

Проведені експериментальні дослідження дозволили встановити, що оптимальне співвідношення між швидкісними параметрами «підвідний конвеєр-додатковий конвеєр» становить $\mathrm{V}_{\text {д }}=1,2 \cdot \mathrm{V}_{\mathrm{n}}$.

Залежність часу переміщення флакона по нерухомій площині від швидкості підвідного конвеєра $\mathrm{V}_{\text {п }}$ при оптимальному значенні кута $\alpha_{\text {опm }}=17^{\circ}$ (рис. 1) для флаконів різного діаметра представлені на рис. 3 .

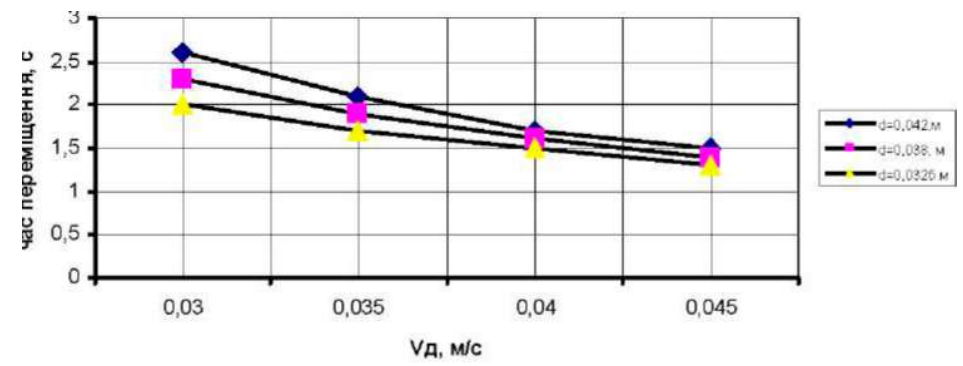

Puc. 3. Залежність часу переміщення флакона по бічній напрямній від швидкості додаткового конвеєра $\mathrm{У}_{\text {п }}$

$$
(\mathrm{V}=1,2-V) \text { для флаконів різного діаметра. }
$$


Висновки. Отримане рівняння складного руху виробів вздовж бічних напрямних на ланці розподілу потоку та здійснена експериментальна перевірка теоретичних положень. Знайдено, що для випадку поступального та зворотно-обертального руху флаконів вздовж бічної напрямної швидкості переміщення центрів мас практично співпадають. Щодо кінце-

\section{Література}

1. Промышленная технология лекарств/ [М.Е. Чернов, М.М.Хохлова, Л.И. Богуславская и др.]; под ред. В.И.Чуешова. [3-е изд]. - Х.: Основа, Издательство УкрФА, 1999. $704 \mathrm{c}$.

2. Губський Т.П. Організація та економіка фармацевтичної справи / Губський Т.П. - К: Вища школа, 1988. - 230с.

3. Погрузочно-разгрузочное и транспортное оборудование в перерабатывающей промышленности: справочник / [Сторижко И.И., Ярешко В. П., Валиулин Г.Р., Юхно М.И.]; под ред. Соколенко А. И. - К: «Урожай», 1990. - 152с.

4. Балашов В.Е. Механизация погрузочно-разгрузочных, вого результату, то можна зробити висновок, що використання додаткового конвеєра при розподілі потоку може мати своє технічне застосування. Хоча, слід відмітити, що організація процесів переміщення вантажів $з$ поступальним рухом енергетично більш вигідна, бо в цьому випадку відсутня кінетична енергія зворотно-обертального руху.

транспортных и складских работ в пиво-безалкогольной промышленности / [Балашов В.Е., Верховский А.С., Моговой В.С.] - М.: Пищевая промышленность. - 1978. - 142с. 5. Рєзнік В.Г. Удосконалення методів розрахунку і обладнання ліній розливу: автореф. дис. на здобуття наук ступеня канд. техн. наук: спец. 05.05.09 «Машини харчої, мікробіологічної та фармацевтичної промисвості»)/ В.Г.Рєзнік. Київ, 1999. -20с.

6. Патент 70461А. Україна МПК 7 В65В5/10. Пристрій для розподілу потоку виробів / Кравець Н.О., Рогатинський Р.М. -№2003098777; заявл 26.09.2003; опубл. 15.10.2004, Бюл №>10. 